\title{
Factors associated with change in exacerbation frequency in COPD
}

\author{
Gavin C Donaldson ${ }^{1 *}$, Hanna Müllerova ${ }^{2}$, Nicholas Locantore ${ }^{3}$, John R Hurst ${ }^{4}$, Peter MA Calverley ${ }^{5}$, Jorgen Vestbo ${ }^{6,7}$,
} Antonio Anzueto ${ }^{8}$ and Jadwiga A Wedzicha ${ }^{1}$

\begin{abstract}
Background: Patients with chronic obstructive pulmonary disease (COPD) can be categorized as having frequent (FE) or infrequent (IE) exacerbations depending on whether they respectively experience two or more, or one or zero exacerbations per year. Although most patients do not change category from year to year, some will, and the factors associated with this behaviour have not been examined.

Methods: 1832 patients completing two year follow-up in the Evaluation of COPD Longitudinally to Identify Predictive Surrogate End-points (ECLIPSE) study were examined at baseline and then yearly. Exacerbations were defined by health care utilisation. Patient characteristics compared between those patients who did or did not change exacerbation category from year 1 to year 2 .
\end{abstract}

Findings: Between years 1 and 2, 221 patients (17\%) changed from IE to FE and 210 patients (39\%) from FE to IE. More severe disease was associated with changing from IE to FE and less severe disease from FE to IE. Over the preceding year, small falls in $\mathrm{FEV}_{1}$ and 6-minute walking distance were associated with changing from IE to FE, and small falls in platelet count associated with changing from FE to IE.

Conclusion: No parameter clearly predicts an imminent change in exacerbation frequency category.

Trial registration: SCO104960, clinicaltrials.gov identifier NCT00292552

Keywords: COPD, Exacerbations, Exacerbation frequency, Exacerbation phenotype

\section{Background}

The natural history of chronic obstructive pulmonary disease (COPD) is punctuated by exacerbations defined as episodes of acute symptomatic deterioration that may warrant a change in treatment $[1,2]$. Frequent exacerbations are associated with reduced quality of life [3], increased airway inflammation [4], accelerated lung func tion decline [5] and increase mortality [6]. Patients with frequent exacerbations make more visits to their medical practitioner, require more medication, experience more hospital admissions [7] and consequently impose a greater financial burden on health services $[8,9]$.

The number of exacerbations a patient experiences over a year is very strongly associated with their frequency in the previous year [3,7]. This stability in

\footnotetext{
* Correspondence: g.donaldson@ucl.ac.uk

${ }^{1}$ Centre for Respiratory Medicine, UCL Medical School, Royal Free Campus, Rowland Hill Street Hampstead, London NW3 2PF, UK

Full list of author information is available at the end of the article
}

exacerbation frequency means that patient recall of events in the previous year can be used to categorize patients as having frequent (FE) or infrequent (IE) exacerbations during the subsequent year $[7,10]$. These categories are now recognised as important COPD patient phenotypes that influence the clinical management of the patient [11]. Although exacerbation frequency is relatively stable in most patients, some year on year variation exists and the factors associated with any change in category have not yet been investigated. Therefore we analysed the data from the "Evaluation of COPD longitudinally to identify predictive surrogate endpoints (ECLIPSE)" study to determine whether patients kept or changed their IE or FE category. Previously, three groups of 0,1 and $2+$ exacerbations per a year have been described [7] but interpretation of the nine potential transitions would be complex and less clinically relevant. In this study, we have also examined a slightly smaller group of 1832 patients who completed two years of

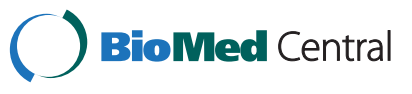


observation rather than the 2138 patients who were enrolled into the ECLIPSE study [7] since the exacerbation frequency measured over both years 1 and 2 was needed to identify patients who did or did not changed IE and FE categories.

Additionally we tried to establish whether specific factors were associated with a change in exacerbation frequency as such data would be useful in identifying patients with an increased risk of a worsening exacerbation frequency and potentially suggest ways to prevent this clinically important change. Some of the results of this study have been previously reported in the form of an abstract [12].

\section{Methods}

\section{Study design and patients}

All patients provided written informed consent and the study was approved by the relevant ethics and review boards ([13]; see online supplement). Eligible patients were aged between 40 and 75 years, with a 10 or more pack-year smoking history, a post-bronchodilator forced expiratory volume in 1 second $\left(\mathrm{FEV}_{1}\right)$ of less than $80 \%$ predicted from age, height and sex [14] and a ratio of $\mathrm{FEV}_{1}$ to forced vital capacity (FVC) of 0.7 or less.

All patients completing at least 2 years of observation are included in this study. Patients underwent comprehensive medical reviews at baseline and then at the end of each 12 months of observation (see Figure 1). Data recorded at the 3, 6 and 18 month visits have not been analysed in this study as data on some patient characteristics were not available at these time points. Patients underwent standard spirometry testing after the administration of $400 \mu \mathrm{g}$ of inhaled albuterol, completed a modified Medical Research Council dyspnoea scale (mMRC) and a St. Georges Respiratory Questionnaire (SGRQ). Co-morbidities were assessed from questions in the American Thoracic Society-Division of Lung Diseases (ATS-DLD) questionnaire and symptoms of depression by the Center for Epidemiologic Studies of Depression (CES-D) questionnaire. A venous blood sample was taken and a medical history including start/stop dates of medications and smoking history recorded. The patients underwent a six minute walking test (6MWD) according to ATS guidelines [15], with distance expressed as a percentage of predicted [16] which was used in calculating the patient's BODE index [17]. Patients also underwent computed tomographic (CT) scanning, at baseline and year 1 , to evaluate the severity of emphysema as the percentage of low attenuation areas (LAA\%) [18].

Blood samples were dispatched immediately after each visit for a full-blood count, and serum and plasma samples stored at $-80^{\circ} \mathrm{C}$ until assayed for fibrinogen, creactive protein (CRP), surfactant protein D (SP-D) and pulmonary activation regulated chemokine (PARC) [19].

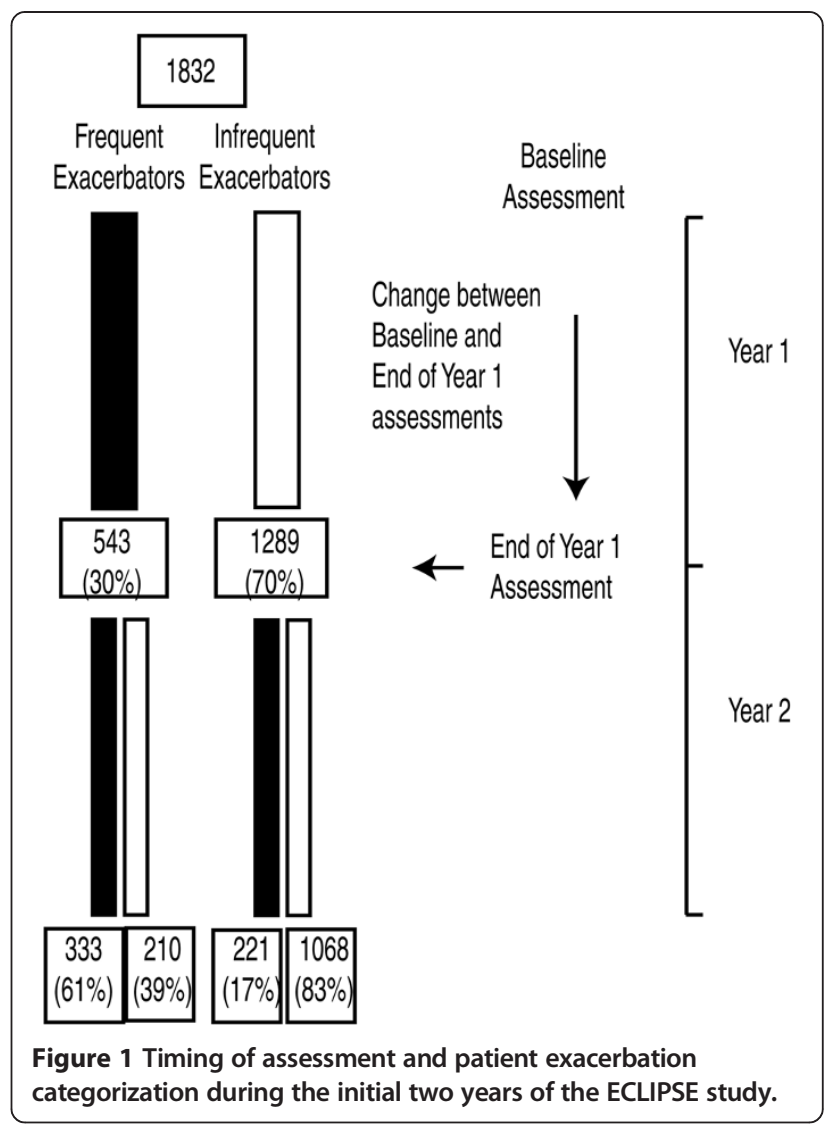

Any samples with values below the lower limit of quantification were assigned a value that was half of the assay lower limit.

Exacerbations were defined by health care utilization requiring the prescription of antibiotics and/or oral corticosteroids by the patient's primary care clinician or study personnel, or hospitalisation for an exacerbation. To ensure capture of these events patients were asked at clinic visits and during monthly telephone calls about visits to health care professionals and change in medications. The end of an exacerbation was based on investigator judgement, and no new exacerbation could start before resolution of an existing exacerbation. Frequent exacerbations were defined as 2 or more per year, and infrequent exacerbations as 1 or zero per year.

\section{Statistical analysis}

Patients were categorized according to their exacerbation frequency assessed over year 1 of follow-up; whether they changed category was assessed using year 2 of follow-up. No data on how many exacerbations the patient recalled experiencing in year prior to recruitment was used in this analysis. Cross-sectional patient characteristics obtained at the year 1 assessment were examined in relation to those who did or did not change category, rather than the baseline assessment, as this 
was closest in time to the point of category change. "Longitudinal" characteristics were calculated as the difference between baseline and the year 1 assessment that is, over the year preceding the point of change in exacerbation frequency (see Figure 1).

Means and standard deviations are reported for the continuous variables, with frequencies reported for the categorical variables. For tests between exacerbation frequency groups, an analysis of variance (ANOVA) for continuous variables or chi-square test for categorical variables was used. Due to skewed distributions, blood and plasma biomarkers were summarized using medians and inter-quartile ranges (IQR). Comparisons of their distributions across exacerbation frequency groups used a Kruskal-Wallis test.

\section{Results}

\section{Change in exacerbation category}

1832 patients completed at least 2 years of follow-up and had data available for this analysis.

543 of the 1832 patients (30\%) had frequent exacerbations and 1289 (70\%) infrequent exacerbations at the end of year 1 of follow-up. Between years 1 and 2, 431 of the 1832 patients (24\%) changed category, 221 (17\%) of the IE patients changed category to FE compared to 210 (39\%) of the FE patients who changed to IE $(\mathrm{P}<0.001)$.

Table 1 shows the demographic characteristics of all 1832 patients recorded at the year 1 assessment, and after division into infrequent (IE) and frequent exacerbator (FE) groups by their observed exacerbation frequency over year 1 .

\section{Change in exacerbation frequency}

Figure 2A shows a histogram for the change in exacerbation frequency between years 1 and 2 of the 1832 patients. $44 \%$ of the patients had an identical exacerbation frequency in years 1 and 2, and for those patients whose exacerbation frequency did change, the magnitude and direct of the changes were evenly distributed around zero. This was consistent with the finding that the number of exacerbations per patient per year (PPPY) was 1.17 in both year 1 and year 2. However, when sub-divided into IE and FE groups, exacerbation frequency was seen to increased from 0.35 PPPY in year 1 to 0.70 PPPY in year 2, while in the FE group, it fell from 3.10 PPPY in year 1 to 2.30 PPPY in year 2 . Figures $2 \mathrm{~B}$ and $2 \mathrm{C}$ show that the distribution of these changes was not symmetrical. In the IE group, the distribution was skewed because exacerbation frequency could not fall by more than 1 exacerbation per year. In the FE group, without such restriction, there was a more even distribution but still many more patients in the -1 and -2 category than in the +1 or +2 category.

\section{Patient characteristics associated with IE to $\mathrm{FE}$, and FE to IE category changes}

Table 2 shows the cross-sectional characteristics of patients at the year 1 assessment, divided into those who did or did not change exacerbation category between years 1 and 2. Patients who changed from IE to FE had worse, and those changing from FE to IE better baseline post-bronchodilator $\mathrm{FEV}_{1}, \mathrm{FEV}_{1} \%$ predicted, mMRC, SGRQ-C, BODE, anxiety and hospitalised exacerbations per patient per year than those who remained in the respective categories. However, some patient characteristics were unique to the direction of change. Patients changing from IE to FE were more likely to be female, have a lower BMI, poorer $\mathrm{FEV}_{1}$ / FVC ratio, less diabetes, more symptoms of depression and more emphysema (LAA\%), but these factors were not different in those who remained FE compared to those who changed from FE to IE. Similarly, for the FE to IE transition, a greater 6MWD and lower systemic inflammation (CRP, Fibrinogen, PARC) were significant factors not seen in IE patients changing to FE.

A total of 116 patients (6.4\%) either started or stopped any maintenance treatment for COPD, i.e. LAMA, LABA, ICS and ICS/LABA combination between baseline and year 1 of follow-up; ninety-five patients (5.2\%) initiated maintenance treatment and 21 (1.2\%) stopped maintenance treatment.

\section{Change in patients characteristics over year 1}

Table 3 shows the "longitudinal" changes in patient characteristics from baseline to the Year 1 assessment that took place before the category transitions. Falls in platelet count were significantly associated with a future category change from FE to IE whereas; falls in $\mathrm{FEV}_{1}$ and in 6MWD were significantly associated with changing from IE to FE. Table 3 also reports differences in the number of exacerbations either hospitalised and/or treated with oral corticosteroids. These two characteristics were assessed over the same time periods as the exacerbation categories and cannot therefore be considered as prospective markers. The patients who changed from IE in year 1 to FE in year 2 had 0.57 hospitalized exacerbation per patient year compared to 0.07 per patient year in IE patients who did not change category. Similarly, there were only 0.14 hospitalised exacerbations per patient year in those changing from FE to IE compared to 0.68 in those who remained FE. These results were consistent with the data on oral corticosteroid treated exacerbations.

\section{Discussion}

This study is the first to examine in a large dataset the factors associated with changes in the exacerbation frequency category of patients with COPD. We had hoped 
Table 1 Patient characteristics at the year 1 assessment: data is presented for all patients and sub-divided by exacerbation category in year 1 of follow-up

\begin{tabular}{|c|c|c|c|c|}
\hline & All COPD $(n=1832)$ & FE $(n=543)$ & IE (n=1289) & p-value FE v IE \\
\hline Age (years) & $64(7)$ & $64(7)$ & $64(7)$ & 0.751 \\
\hline Females (\%) & $35 \%$ & $41 \%$ & $32 \%$ & $<0.001$ \\
\hline BMI (kg/m2) & $27(6)$ & $26(6)$ & $27(6)$ & 0.006 \\
\hline Active smoker (\%) & $36 \%$ & $33 \%$ & $37 \%$ & 0.113 \\
\hline${ }^{*}$ FEV1 (L) & $1.37(0.55)$ & $1.14(0.45)$ & $1.47(0.55)$ & $<0.001$ \\
\hline${ }^{*}$ FEV1 \%predicted & $49(16)$ & $43(16)$ & $52(16)$ & $<0.001$ \\
\hline${ }^{*} \mathrm{FEV} 1 / \mathrm{FVC} \%$ & $45(12)$ & $41(12)$ & $46(12)$ & $<0.001$ \\
\hline 6-minute walk distance $(\mathrm{m})$ & $385(123)$ & $350(119)$ & $399(122)$ & $<0.001$ \\
\hline \%predicted 6MWD & $74(24)$ & $69(23)$ & $77(23)$ & $<0.001$ \\
\hline Blood oxygen saturation (\%) & $94.7(2.9)$ & $94.2(3.1)$ & $94.9(2.8)$ & $<0.001$ \\
\hline Emphysema LAA\% (-950HU) & $18(12)$ & $20(13)$ & $17(12)$ & $<0.001$ \\
\hline mMRC Dyspnoea Score & $1.7(1.1)$ & $2.0(1.1)$ & $1.5(1.0)$ & $<0.001$ \\
\hline SGRQ-C Total Score & $47(21)$ & $57(18)$ & $43(21)$ & $<0.001$ \\
\hline BODE Index & $3.0(2.1)$ & $3.9(2.2)$ & $2.7(2.0)$ & $<0.001$ \\
\hline White blood cells $(10 \wedge 9 / L)$ & $7.6(2.2)$ & $8.1(2.4)$ & $7.4(2.0)$ & $<0.001$ \\
\hline Platelets $(10 \wedge 9 / L)$ & $266(71)$ & $276(75)$ & $261(69)$ & 0.002 \\
\hline Fibrinogen (mg/dL) & $436[383-504]$ & 468 [405-535] & $426[376-492]$ & $<0.001$ \\
\hline $\mathrm{CRP}(\mathrm{mg} / \mathrm{dL})$ & $3.3[1.5-7.3]$ & $4.1[1.8-9.1]$ & $3.1[1.4-6.6]$ & $<0.001$ \\
\hline $\mathrm{SP}-\mathrm{D}(\mathrm{ng} / \mathrm{mL})$ & 119 [87-163] & 115 [86-159] & $121[87-166]$ & 0.294 \\
\hline PARC/CCL-18 (ng/mL) & 112 [87-145] & 119 [92-154] & 111 [85-141] & 0.001 \\
\hline Neutrophils $(10 \wedge 9 / L)$ & $5.0(1.9)$ & $5.4(2.2)$ & $4.8(1.8)$ & $<0.001$ \\
\hline Treated with ICSL \% & $71 \%$ & $81 \%$ & $66 \%$ & 0.159 \\
\hline Treated with LAMA \% & $63 \%$ & $68 \%$ & $60 \%$ & $<0.001$ \\
\hline Treated with ICS \% & $17 \%$ & $15 \%$ & $17 \%$ & 0.336 \\
\hline Treated with LABA \% & $14 \%$ & $14 \%$ & $15 \%$ & 0.813 \\
\hline Treated with Oxygen \% & $10 \%$ & $16 \%$ & $6 \%$ & $<0.001$ \\
\hline PPPY COPD Hosp. Year 1 & 0.20 & 0.55 & 0.05 & $<0.001$ \\
\hline PPPY OCS only exbs Y1 & 0.13 & 0.35 & 0.04 & $<0.001$ \\
\hline Diabetes & $10 \%$ & $8 \%$ & $10 \%$ & 0.287 \\
\hline Cardiovascular (excl. HTN) & $33 \%$ & $32 \%$ & $33 \%$ & 0.868 \\
\hline Reflux/heartburn & $26 \%$ & $33 \%$ & $23 \%$ & $<0.001$ \\
\hline Anxiety & $16 \%$ & $21 \%$ & $14 \%$ & $<0.001$ \\
\hline Depression symptoms & $25 \%$ & $33 \%$ & $21 \%$ & $<0.001$ \\
\hline
\end{tabular}

P-values are for comparisons between patients with Frequent (FE) and Infrequent exacerbations (IE). Mean (SD) or Median [25\% - 75\% percentile].

to identify a parameter that might prospectively alert physicians to an imminent change in category but no single parameter emerged. Those variables that did change in the year before IE patients became frequent exacerbators (falls in $\mathrm{FEV}_{1}$ and 6-minute walking distance) or FE patients switched to IE (fall in platelet count) were too small in magnitude relative to the overall variability to provide a useful predictive tool. We did observe more hospitalized exacerbations in those changing from IE to $\mathrm{FE}$, and fewer hospitalized exacerbations in those changing from FE to IE, compared to those patients who remained in their category. Since, the number of hospitalized exacerbation over year 1 partly determined how the patients were categorized; this parameter could not be considered sufficiently independent or prospective for predicting a change in category. However, it is possible that the presence, or absence, of exacerbations severe enough to warrant hospital admission indicates a transition in the trajectory of the disease. Our results highlight the multi-facetted nature of the disease 

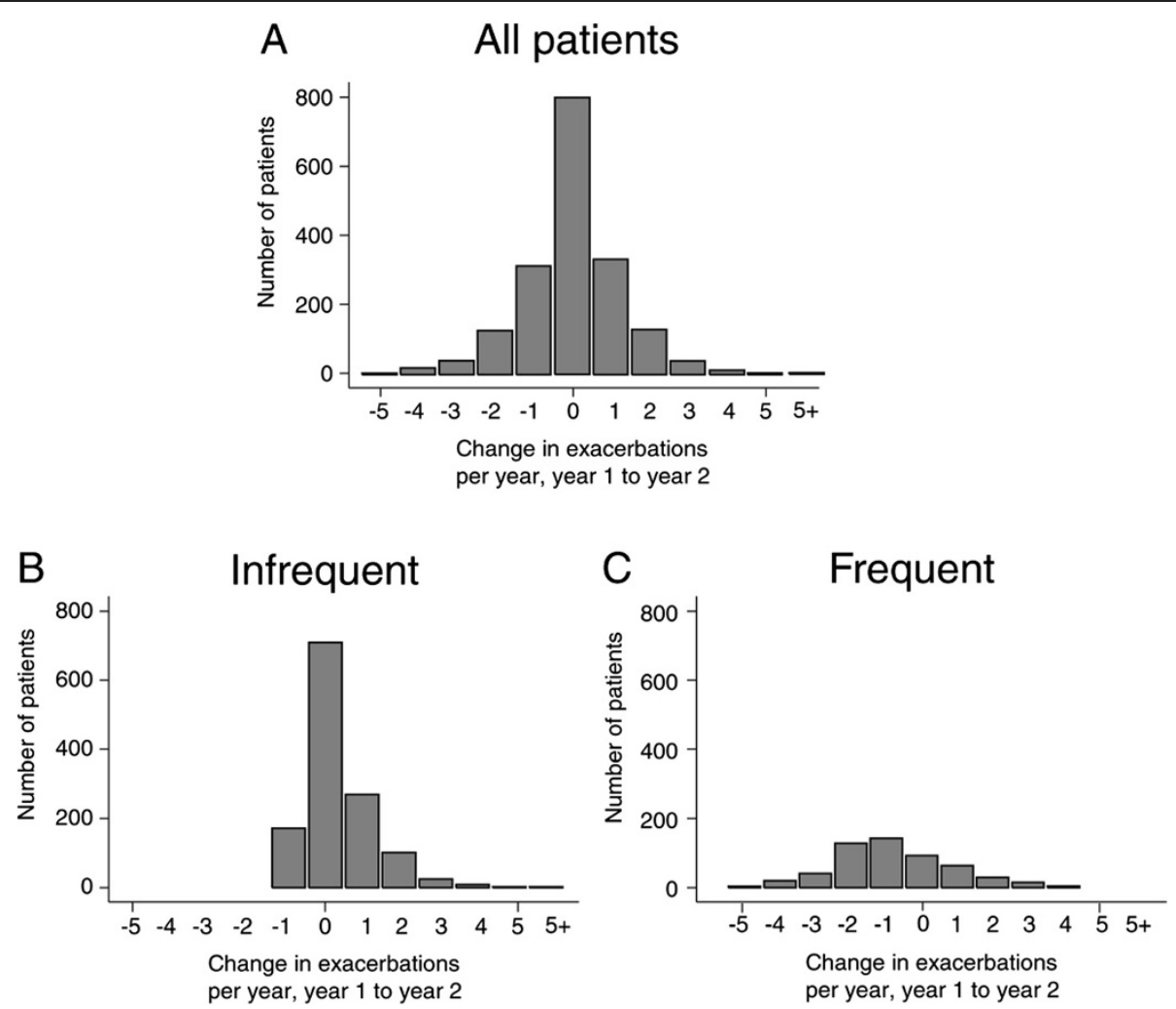

Figure 2 Distribution of exacerbation frequency change. All COPD patients (A) and in patients classified as IE (B) and FE (C) in year 1.

and suggests that all patients are at risk of developing the frequent exacerbator phenotype.

Across the whole study population, exacerbation frequency was unchanged in year 2 compared to year 1 . This agrees with another observational study that found no change in exacerbation frequency over 6 years of follow-up albeit with a symptomatic definition of exacerbation [20]. Aaron and colleagues have reported with transitional regression models that patients experience a significant acceleration in the rate of exacerbations over just one year [21]. It might be that changes in interexacerbation intervals provide a more sensitive measure of changes in exacerbation frequency over time, but this metric lacks the simplicity required for clinical assessment. We observed that $44 \%$ of patients had no change in exacerbation frequency between years 1 and 2 . In the remaining $56 \%$ of patients, the changes in frequency had a bell-shaped distribution with an approximately equal number of rises and falls. This could simply be "regression to the mean" but there will also be some random variability in the number of viruses and bacteria circulating in the community which are thought to trigger the majority of COPD exacerbations [22,23].

The rise in exacerbation frequency that we observed in the IE group could involve four factors. Firstly, our definition of IE as 0 or 1 exacerbation per a year meant that falls in exacerbation frequency were restricted to a maximum of -1 per year, but there was no limit to any rise in frequency, and the maximum increase we observed was +10 per year. Secondly, COPD progresses and higher exacerbation frequencies are more likely to be reported in more severe patients [24]. We found that the patients who changed from IE to FE were generally more severe than those who stayed in the IE group over a wide range of patient characteristics. Thirdly, some patient characteristics fell over the year preceding the change from IE to FE. An acute deterioration is occasionally observed in clinical practice but the underlying reasons for the change are not totally recognised. The physiological markers that worsened relative to the normal reduction observed in those patients who did not change category were $\mathrm{FEV}_{1}$ and 6MWD. These are important indicators of COPD severity, with rapid decline in both $\mathrm{FEV}_{1}$ [25] and 6MWD [26] associated with increased mortality. Unfortunately, the magnitude of the falls in $\mathrm{FEV}_{1}$ and 6MWD were small compared to their overall variability and thus would not make useful targets for monitoring risk or early intervention. Fourthly, it is possible that exacerbation frequency changed because patients started to seek treatment for previously unreported exacerbations or increased their adherence to already prescribed treatments. About $50 \%$ of exacerbations in patients with moderate to severe COPD 
Table 2 Patient characteristics at year 1 assessment split by exacerbation phenotype over study years 1 and 2

\begin{tabular}{|c|c|c|c|c|c|c|}
\hline \multirow{2}{*}{$\begin{array}{l}\text { Year } 1 \text { Category } \\
\text { Year } 2 \text { Category }\end{array}$} & \multicolumn{3}{|c|}{ Year 1 IE $(n=1289)$} & \multicolumn{3}{|c|}{ Year 1 FE $(n=543)$} \\
\hline & $\begin{array}{c}\text { Stayed as IE } \\
(n=1068)\end{array}$ & $\begin{array}{l}\text { Change to FE } \\
(n=221)\end{array}$ & p-value & $\begin{array}{c}\text { Stayed as FE } \\
(n=333)\end{array}$ & $\begin{array}{l}\text { Change to IE } \\
(n=210)\end{array}$ & p-value \\
\hline \multicolumn{7}{|c|}{ Characteristics at Year 1 Assessment } \\
\hline Age (years) & $64(7)$ & $64(7)$ & 0.496 & $64(7)$ & $65(7)$ & 0.508 \\
\hline Females (\%) & $31 \%$ & $41 \%$ & 0.002 & $42 \%$ & $40 \%$ & 0.561 \\
\hline BMI (kg/m2) & $27(6)$ & $26(5)$ & 0.007 & $26(6)$ & $26(5)$ & 0.918 \\
\hline Active smoker (\%) & $37 \%$ & $35 \%$ & 0.646 & $33 \%$ & $32 \%$ & 0.776 \\
\hline${ }^{*} \mathrm{FEV} 1(\mathrm{~L})$ & $1.52(0.56)$ & $1.23(0.45)$ & $<0.001$ & $1.09(0.41)$ & $1.23(0.50)$ & $<0.001$ \\
\hline${ }^{*}$ FEV1 \%predicted & $53(16)$ & $45(15)$ & $<0.001$ & $41(15)$ & $46(16)$ & 0.001 \\
\hline *FEV1/FVC \% & $47(12)$ & $43(11)$ & $<0.001$ & $41(11)$ & $43(12)$ & 0.098 \\
\hline 6-minute walk distance $(\mathrm{m})$ & $402(124)$ & $388(114)$ & 0.125 & $339(125)$ & $368(107)$ & 0.006 \\
\hline \%predicted 6MWD & $77(23)$ & $76(22)$ & 0.480 & $66(24)$ & $73(21)$ & 0.002 \\
\hline Blood oxygen saturation (\%) & $95.0(2.8)$ & $94.4(2.7)$ & 0.012 & $93.9(3.2)$ & $94.5(2.7)$ & 0.031 \\
\hline Emphysema LAA\% (-950HU) & $16(12)$ & $20(13)$ & $<0.001$ & $21(13)$ & $19(13)$ & 0.126 \\
\hline mMRC Dyspnoea Score & $1.5(1.0)$ & $1.7(1.1)$ & 0.004 & $2.1(1.0)$ & $1.8(1.1)$ & $<0.001$ \\
\hline SGRQ Total Score & $41(18)$ & $47(19)$ & $<0.001$ & $57(16)$ & $50(16)$ & $<0.001$ \\
\hline BODE Index & $2.5(1.9)$ & $3.3(2.0)$ & $<0.001$ & $4.2(2.2)$ & $3.4(2.2)$ & $<0.001$ \\
\hline White blood cells $(10 \wedge 9 / L)$ & $7.4(2.0)$ & $7.5(2.2)$ & 0.926 & $8.2(2.5)$ & $7.9(2.1)$ & 0.082 \\
\hline Neutrophils, (10^9/L) & $4.8(1.7)$ & $4.9(2.1)$ & 0.601 & $5.6(2.4)$ & $5.2(1.9)$ & 0.084 \\
\hline Platelets $(10 \wedge 9 / L)$ & $261(70)$ & $263(69)$ & 0.713 & $281(77)$ & $268(70)$ & 0.055 \\
\hline Fibrinogen (mg/dL) & 423 [376-490] & 438 [380-502] & 0.092 & 480 [416-543] & 444 [388-508] & $<0.001$ \\
\hline CRP (mg/dL) & $3.0[1.4-6.5]$ & $3.4[1.6-7.6]$ & 0.071 & $4.7[2.1-10.4]$ & $3.1[1.6-6.9]$ & 0.002 \\
\hline SP-D (ng/mL) & $121[86-167]$ & 125 [89-162] & 0.625 & 116 [85-162] & 114 [88-157] & 0.651 \\
\hline PARC/CCL-18 (ng/mL) & $111[86-141]$ & 110 [83-141] & 0.943 & $121[94-162]$ & 113 [87-145] & 0.027 \\
\hline PPPY COPD Hosp. Year 1 & 0.04 & 0.12 & $<0.001$ & 0.65 & 0.38 & 0.004 \\
\hline PPPY OCS only exbs Y1 & 0.04 & 0.05 & 0.218 & 0.38 & 0.29 & 0.218 \\
\hline Diabetes & $11 \%$ & $6 \%$ & 0.024 & $8 \%$ & $9 \%$ & 0.689 \\
\hline $\begin{array}{l}\text { Cardiovascular (excluding } \\
\text { HTN) }\end{array}$ & $33 \%$ & $33 \%$ & 0.904 & $29 \%$ & $37 \%$ & 0.072 \\
\hline Reflux/heartburn & $23 \%$ & $23 \%$ & 0.890 & $32 \%$ & $33 \%$ & 0.888 \\
\hline Anxiety & $13 \%$ & $20 \%$ & 0.003 & $24 \%$ & $16 \%$ & 0.022 \\
\hline Depression symptoms & $20 \%$ & $29 \%$ & 0.004 & $36 \%$ & $28 \%$ & 0.058 \\
\hline
\end{tabular}

P-values are comparisons between those who stayed in or changed exacerbation category. Data are mean (SD) or median [25\% - 75\% percentile].

are unreported [3]. Unreported exacerbations are generally similar to reported exacerbations in symptoms and spirometric changes [27] and contribute to a poorer quality of life $[28,29]$ but there is much heterogeneity of reporting behaviour and even some patients with severe airflow obstruction will not report exacerbations [30].

We observed that a significant falls in platelet count occurred over the year proceeding patients changing from the FE to IE group but the standard deviation of these changes was too large to be of clinical utility. Platelet count has been found to be elevated in COPD compared to healthy controls [31] and increases during lower respiratory tract infection [32]. Platelets are not only involved in haemostasis but produce a broad array of inflammatory mediators and factors that alter innate and adaptive immunity $[33,34]$. We speculate that a reduced platelet count is indicative of reduced airway inflammation or improvement in immunity to infection thus reducing susceptibility to future exacerbation. There is also emerging evidence that statins, which reduce platelet-activation [35], have the potential to reduce exacerbation frequency in COPD [36].

The relatively large proportion of patients changing from FE to IE could also be explained by the method by which exacerbation frequency was assessed. A number of patients could be experiencing three exacerbations 
Table 3 Change in COPD patient characteristics between baseline and year 1 assessment

\begin{tabular}{|c|c|c|c|c|c|c|}
\hline \multirow{2}{*}{$\begin{array}{l}\text { Year } 1 \text { Category } \\
\text { Year } 2 \text { Category }\end{array}$} & \multicolumn{3}{|c|}{ Year 1 IE $(n=1289)$} & \multicolumn{3}{|c|}{ Year 1 FE $(n=543)$} \\
\hline & Stayed as IE $(n=1068)$ & Change to FE $(n=221)$ & $\overline{\text { p-value }}$ & Stayed as FE $(n=333)$ & Change to IE $(n=210)$ & $\overline{p \text {-value }}$ \\
\hline \multicolumn{7}{|c|}{ Change in patient measures (year 1 assessment - baseline) } \\
\hline $\mathrm{BMI}(\mathrm{kg} / \mathrm{m} 2)$ & $0.0(1.4)$ & $0.0(1.1)$ & 0.750 & $-0.1(1.4)$ & $-0.1(1.6)$ & 0.589 \\
\hline FEV1 (mL) & $14(233)$ & $-46(184)$ & $<0.001$ & $-32(180)$ & $-22(217)$ & 0.543 \\
\hline FEV1 $\%$ predicted & $0.4(7.7)$ & $-1.6(6.9)$ & $<0.001$ & $-1.1(6.4)$ & $-0.9(7.8)$ & 0.690 \\
\hline FEV1/FVC \% & $-0.1(5.8)$ & $-0.4(5.2)$ & 0.534 & $-0.3(6.0)$ & $-0.9(6.0)$ & 0.250 \\
\hline${ }^{*}$ Changed smoking status & $6 \%$ & $9 \%$ & 0.053 & $6 \%$ & $9 \%$ & 0.153 \\
\hline${ }^{*}$ Re-Started smoking (\%) & $5 \%$ & $9 \%$ & 0.051 & $4 \%$ & $4 \%$ & 0.726 \\
\hline *Stopped smoking (\%) & $7 \%$ & $10 \%$ & 0.448 & $9 \%$ & $17 \%$ & 0.125 \\
\hline 6-min walk distance (m) & $10(90)$ & $-5(85)$ & 0.036 & $-6(94)$ & $-1(84)$ & 0.568 \\
\hline Blood oxygen saturation (\%) & $0.0(2.9)$ & $-0.1(3.0)$ & 0.478 & $-0.3(3.3)$ & $-0.2(2.8)$ & 0.713 \\
\hline mMRC Dyspnoea Score & $0.0(0.9)$ & $0.0(1.0)$ & 0.682 & $0.1(1.0)$ & $0.0(1.0)$ & 0.691 \\
\hline SGRQ Total Score & $-2.0(10.6)$ & $-1.9(12.1)$ & 0.879 & $-0.1(9.9)$ & $-0.1(10.2)$ & 0.986 \\
\hline BODE Index & $0.0(1.2)$ & $0.1(1.3)$ & 0.138 & $0.2(1.5)$ & $0.1(1.3)$ & 0.424 \\
\hline White blood cells $(10 \wedge 9 / L)$ & $-0.3(1.6)$ & $-0.2(1.9)$ & 0.606 & $0.0(2.3)$ & $-0.2(2.1)$ & 0.289 \\
\hline Neutrophils $(10 \wedge 9 / L)$ & $-0.2(1.5)$ & $-0.2(1.9)$ & 0.894 & $0.2(2.3)$ & $-0.1(2.0)$ & 0.232 \\
\hline Platelets $(10 \wedge 9 / L)$ & $-7(47)$ & $-11(41)$ & 0.238 & $-5(51)$ & $-16(49)$ & 0.014 \\
\hline Fibrinogen (mg/dL) & $-6[-51,36]$ & $0[-38,41]$ & 0.151 & $5[-41,58]$ & $-3[-52,38]$ & 0.109 \\
\hline CRP (mg/dL) & $0.1[-1.3,1.5]$ & $0.0[-1.8,2.1]$ & 0.999 & $0.3[-1.4,3.0]$ & $-0.2[-2.4,1.9]$ & 0.083 \\
\hline SP-D (ng/mL) & $0[-18,20]$ & $0[-23,26]$ & 0.654 & $-1[-24,24]$ & $0[-21,21]$ & 0.806 \\
\hline PARC/CCL-18 (ng/mL) & $6[-6,21]$ & $6[-9,23]$ & 0.628 & $9[-6,27]$ & $6[-7,21]$ & 0.114 \\
\hline \multicolumn{7}{|c|}{ Change between the number of events in year 1 and in year 2} \\
\hline PPPY COPD Hosp. Year 2 & 0.07 & 0.57 & $<0.001$ & 0.68 & 0.14 & $<0.001$ \\
\hline PPPY OCS only exbs Y2 & 0.04 & 0.25 & $<0.001$ & 0.37 & 0.06 & $<0.001$ \\
\hline
\end{tabular}

P-values are comparisons between those who stayed in or changed exacerbation category. Mean (SD) or Median [25\% - 75\% percentile].

* - "Stopped smoking" are the current smokers at baseline who stopped before Year 1, "Re-started smoking" are the former smokers at baseline who started again before Year 1.

over a two year period, with for example, two exacerbations in year 1 and then one exacerbation in year 2 . They would initially be categorized as FE but change to IE in the following year. Another possibility is that that patients who normally experience two exacerbations per year change to having 3 in one year and 1 in the next year, because they have an exacerbation just before, rather than just after, the division between years. Another explanation is that participation in an observational study reduces anxiety and/or improving adherence to treatment with a consequential fall in exacerbation frequency.

There are a number of limitations concerning the major findings that should be mentioned. A practice $6 \mathrm{MWD}$ test was not performed and approximately $6 \%$ of the results might have differed if this rehearsal had this been undertaken [37]. The declines observed in $\mathrm{FEV}_{1}$ in the Eclipse study [38] were modest but in-line with a recent interventional study [39]. Measurements of $\mathrm{FEV}_{1}$ and blood cell counts may have affected by exacerbations that took longer than 30 days to resolved, by the development of comorbidities or initiation of pulmonary rehabilitation. The analysis was based on change in the total number of exacerbations and we did not examine the data by change in the number of hospitalized or oral corticosteroid treated exacerbations.

Amongst the strengths of this study was the follow-up of a large number of COPD patients with systematic measurements on a wide variety of patient characteristics. The patients were recruited worldwide from primary and secondary care and thus the results are generalizable to clinical practice in COPD. We did not feel that changes in oral or inhaled medication were responsible for a change in exacerbation phenotype. Our reasons were the very small proportion of patients involved and the impossibility to determining whether any change in treatment was in response to a rise in exacerbation frequency or to preempt an increase.

\section{Conclusion}

Exacerbation frequency has been shown to be an important phenotype in COPD. A few patients may shift from one category to another. There is no clear explanation or 
marker apart from the fact that patients on the borderline between infrequent and frequent exacerbations are more likely to change category. Thus, physicians need to consider that all patients are at risk during the course of the disease of becoming a frequent exacerbator.

\section{Abbreviations}

BMI: Body Mass Index; ICSL: Inhaled corticosteroid and long-acting b2agonist combination; LAMA: Long acting muscarinic antagonist; ICS: Inhaled corticosteroid; LABA: Long-acting b2-agonist; OCS: Oral corticosteroid; HTN: Hypertension; HU: Hounsfield units; Hosp: Hospitalized exacerbation; PPPY: Per patient per year.

\section{Competing interests}

GlaxoSmithKline funded the ECLIPSE study. The authors conceived and planned the current analyses and were responsible for decisions with regard to publication. The study sponsor did not place any restrictions with regard to statements made in the final paper. GD has had support from GSK to attend Eclipse meetings; HM and NL are employees of GSK; JH has had support from GSK to attend Eclipse meetings and received payments for lectures; PC had had funding from GSK for the Eclipse study; meetings; membership of the scientific committees of TORCH, ECLIPSE and SUMMIT and for lectures; JV has received funding from GSK for consultancy for the COPD phase $2 \& 3$ program and for lectures, his wife previously worked for GSK; AA has received funding from GSK for consultancy, honoraria and lectures; JW has had funding from GSK for lectures, grants and board membership. The authors have all received funding from other pharmaceutical companies.

\section{Authors' contributions}

Study idea and design: HM, GD, JW. Statistical Analysis: HM, NL. Interpretation of results: GC, HM, NL, JH, PC, JV, AA, JW. Manuscript drafting/ revision: GC, HM, JH, PC, JV, AA, JW. All authors read and approved the final manuscript.

\section{Acknowledgments}

This work was funded by GlaxoSmithKline. The authors acknowledge the principle investigators, steering and scientific committee of the ECLIPSE study. The authors would also like to thank the patients participating in the ECLIPSE study.

\section{Author details}

${ }^{1}$ Centre for Respiratory Medicine, UCL Medical School, Royal Free Campus, Rowland Hill Street Hampstead, London NW3 2PF, UK. ${ }^{2}$ GlaxoSmithKline R\&D, Building 9, Iron Bridge Road, Stockley Park West, Uxbridge, Middlesex UB11 1BT, UK. ${ }^{3}$ GlaxoSmithKline, Research Triangle Park, NC, USA. ${ }^{4}$ Centre of Inflammation and Tissue Repair, University College London, London, UK. ${ }^{5}$ School of Ageing and Chronic Disease, University Hospital Aintree, Lower Lane, Liverpool L9 7AL, UK. ${ }^{6}$ Department of Respiratory Medicine, Odense University Hospital and University of Southern Denmark, Odense, Denmark. ${ }^{7}$ Respiratory Research Group, School of Translational Medicine, Manchester Academic Health Sciences Centre, University of Manchester, Manchester, UK ${ }^{8}$ Pulmonary Section, University of Texas Health Science Center, and South Texas Veterans Health Care System, San Antonio, TX, USA.

Received: 25 April 2013 Accepted: 25 July 2013

Published: 30 July 2013

\section{References}

1. Wedzicha JA, Seemungal TA: COPD exacerbations: defining their cause and prevention. Lancet 2007, 370:786-796.

2. Wedzicha JA, Donaldson GC: Exacerbations of chronic obstructive pulmonary disease. Respir Care 2003, 48:1204-1213.

3. Seemungal TA, Donaldson GC, Paul EA, Bestall JC, Jeffries DJ, Wedzicha JA: Effect of exacerbation on quality of life in patients with chronic obstructive pulmonary disease. Am J Respir Crit Care Med 1998, 157:1418-1422.

4. Bhowmik A, Seemungal TA, Sapsford RJ, Wedzicha JA: Relation of sputum inflammatory markers to symptoms and lung function changes in COPD exacerbations. Thorax 2000, 55:114-120.
5. Donaldson G, Seemungal TA, Bhowmik A, Wedzicha JA: Relationship between exacerbation frequency and lung function decline in chronic obstructive pulmonary disease. Thorax 2002, 57:847-852.

6. Soler-Cataluna JJ, Martinez-Garcia MA: Roman Sanchez P, Salcedo E, Navarro M, Ochando R: Severe acute exacerbations and mortality in patients with chronic obstructive pulmonary disease. Thorax 2005, 60:925-931.

7. Hurst JR, Vestbo J, Anzueto A, Locantore N, Mullerova H, Tal-Singer R, Miller B, Lomas DA, Agusti A, Macnee W, et al: Susceptibility to exacerbation in chronic obstructive pulmonary disease. N Engl I Med 2010, 363:1128-1138.

8. McGuire A, Irwin DE, Fenn P, Gray A, Anderson P, Lovering A, MacGowan A: The excess cost of acute exacerbations of chronic bronchitis in patients aged 45 and older in England and Wales. Value in health: the journal of the International Society for Pharmacoeconomics and Outcomes Research 2001, 4:370-375.

9. Borg S, Ericsson A, Wedzicha J, Gulsvik A, Lundback B, Donaldson GC, Sullivan SD: A computer simulation model of the natural history and economic impact of chronic obstructive pulmonary disease. Value Health 2004, 7:153-167.

10. Quint JK, Donaldson GC, Hurst JR, Goldring JJ, Seemungal TR, Wedzicha JA: Predictive accuracy of patient-reported exacerbation frequency in COPD. The European respiratory journal: official journal of the European Society for Clinical Respiratory Physiology 2011, 37:501-507.

11. Vestbo J, Hurd SS, Agusti AG, Jones PW, Vogelmeier C, Anzueto A, Barnes PJ, Fabbri LM, Martinez FJ, Nishimura M, et al: Global Strategy for the Diagnosis, Management and Prevention of Chronic Obstructive Pulmonary Disease, GOLD Executive Summary. Am J Respir Crit Care Med 2013, 187:347-365.

12. Donaldson GC, Mullerova H, Locantore NW, Hurst JR, Vestbo J, Anzueto A, Wedzicha JA: Factors Associated With Change In COPD Exacerbation Frequency Phenotype. J Respir Crit Care Med 2011, 183:A5362.

13. Vestbo J, Anderson W, Coxson HO, Crim C, Dawber F, Edwards L, Hagan G, Knobil K, Lomas DA, MacNee W, et al: Evaluation of COPD Longitudinally to Identify Predictive Surrogate End-points (ECLIPSE). The European respiratory journal: official journal of the European Society for Clinical Respiratory Physiology 2008, 31:869-873.

14. Quanjer PH, Tammeling GJ, Cotes JE, Pedersen OF, Peslin R, Yernault JC: Lung volumes and forced ventilatory flows. Report Working Party Standardization of Lung Function Tests, European Community for Steel and Coal. Official Statement of the European Respiratory Society. Eur Respir J Suppl 1993, 16:5-40.

15. Spruit MA, Watkins ML, Edwards LD, Vestbo J, Calverley PM, Pinto-Plata V, Celli BR, Tal-Singer R, Wouters EF: Determinants of poor 6-min walking distance in patients with COPD: the ECLIPSE cohort. Respir Med 2010, 104:849-857.

16. Enright PL, Sherrill DL: Reference equations for the six-minute walk in healthy adults. Am J Respir Crit Care Med 1998, 158:1384-1387.

17. Celli BR, Cote CG, Marin JM, Casanova C, Montes De Oca M, Mendez RA, Pinto Plata V, Cabral HJ: The body-mass index, airflow obstruction, dyspnea, and exercise capacity index in chronic obstructive pulmonary disease. N Engl J Med 2004, 350:1005-1012.

18. Gietema HA, Muller NL, Fauerbach PV, Sharma S, Edwards LD, Camp PG, Coxson HO: Quantifying the extent of emphysema: factors associated with radiologists' estimations and quantitative indices of emphysema severity using the ECLIPSE cohort. Acad Radiol 2011, 18:661-671.

19. Dickens JA, Miller BE, Edwards LD, Silverman EK, Lomas DA, Tal-Singer R: COPD association and repeatability of blood biomarkers in the ECLIPSE cohort. Respir Res 2011, 12:146.

20. Donaldson GC, Seemungal TA, Patel IS, Lloyd-Owen SJ, Wilkinson TM, Wedzicha JA: Longitudinal changes in the nature, severity and frequency of COPD exacerbations. Eur Respir J 2003, 22:931-936.

21. Aaron SD, Ramsay T, Vandemheen K, Whitmore GA: A threshold regression model for recurrent exacerbations in chronic obstructive pulmonary disease. J Clin Epidemiol 2010, 63:1324-1331.

22. Wilkinson TMA, Hurst JR, Perera WR, Wilks M, Donaldson GC, Wedzicha JA: Effect of interactions between lower airway bacterial and rhinoviral infection in exacerbations of COPD. Chest 2006, 129:317-324.

23. Seemungal T, Harper-Owen R, Bhowmik A, Moric I, Sanderson G, Message S, Maccallum P, Meade TW, Jeffries DJ, Johnston SL, Wedzicha JA: Respiratory viruses, symptoms, and inflammatory markers in acute exacerbations 
and stable chronic obstructive pulmonary disease. Am J Respir Crit Care Med 2001, 164:1618-1623.

24. Hoogendoorn M, Feenstra TL, Hoogenveen RT, Al M, Molken MR: Association between lung function and exacerbation frequency in patients with COPD. Int J Chron Obstruct Pulmon Dis 2010, 5:435-444.

25. Mannino DM, Davis KJ: Lung function decline and outcomes in an elderly population. Thorax 2006, 61:472-477.

26. Pinto-Plata VM, Cote C, Cabral H, Taylor J, Celli BR: The 6-min walk distance: change over time and value as a predictor of survival in severe COPD. The European respiratory journal: official journal of the European Society for Clinical Respiratory Physiology 2004, 23:28-33.

27. Seemungal TA, Donaldson GC, Bhowmik A, Jeffries DJ, Wedzicha JA: Time course and recovery of exacerbations in patients with chronic obstructive pulmonary disease. Am J Respir Crit Care Med 2000, 161:1608-1613.

28. Wilkinson TM, Donaldson GC, Hurst JR, Seemungal TA, Wedzicha JA: Early therapy improves outcomes of exacerbations of chronic obstructive pulmonary disease. Am J Respir Crit Care Med 2004, 169:1298-1303.

29. Xu W, Collet JP, Shapiro S, Lin Y, Yang T, Wang C, Bourbeau J: Negative impacts of unreported COPD exacerbations on health-related quality of life at 1 year. The European respiratory journal: official journal of the European Society for Clinical Respiratory Physiology 2010, 35:1022-1030

30. Agusti A, Calverley PM, Celli B, Coxson HO, Edwards LD, Lomas DA, MacNee W, Miller BE, Rennard S, Silverman EK, et al: Characterisation of COPD heterogeneity in the ECLIPSE cohort. Respir Res 2010, 11:122.

31. Biljak VR, Pancirov D, Cepelak I, Popovic-Grle S, Stjepanovic G, Grubisic TZ: Platelet count, mean platelet volume and smoking status in stable chronic obstructive pulmonary disease. Platelets 2011, 22:466-470.

32. Vlacha $\mathrm{V}$, Feketea $\mathrm{G}$ : Thrombocytosis in pediatric patients is associated with severe lower respiratory tract inflammation. Arch Med Res 2006 37:755-759.

33. Pitchford SC: Novel uses for anti-platelet agents as anti-inflammatory drugs. Br J Pharmacol 2007, 152:987-1002.

34. Ferroni P, Vazzana N, Riondino S, Cuccurullo C, Guadagni F, Davi G: Platelet Function in Health and Disease: from Molecular Mechanisms, Redox Considerations to Novel Therapeutic Opportunities. Antioxid Redox Signal 2012, 17:1447-1485.

35. Tsai NW, Lin TK, Chang WN, Jan CR, Huang CR, Chen SD, Cheng KY, Chiang YF, Wang HC, Yang TM, et al: Statin pre-treatment is associated with lower platelet activity and favorable outcome in patients with acute non-cardio-embolic ischemic stroke. Crit Care 2011, 15:R163.

36. Huang CC, Chan WL, Chen YC, Chen TJ, Chou KT, Lin SJ, Chen JW, Leu HB: Statin Use and Hospitalization in Patients with Chronic Obstructive Pulmonary Disease: A Nationwide Population-Based Cohort Study in Taiwan. Clin Ther 2011, 33:1365-1370.

37. Hernandes NA, Wouters EF, Meijer K, Annegarn J, Pitta F, Spruit MA: Reproducibility of 6-minute walking test in patients with COPD. The European respiratory journal: official journal of the European Society for Clinical Respiratory Physiology 2011, 38:261-267.

38. Vestbo J, Edwards LD, Scanlon PD, Yates JC, Agusti A, Bakke P, Calverley PM, Celli B, Coxson HO, Crim C, et al: Changes in forced expiratory volume in 1 second over time in COPD. N Engl J Med 2011, 365:1184-1192.

39. Tashkin DP, Celli B, Senn S, Burkhart D, Kesten S, Menjoge S, Decramer M: A 4-year trial of tiotropium in chronic obstructive pulmonary disease. N Engl J Med 2008, 359:1543-1554.

doi:10.1186/1465-9921-14-79

Cite this article as: Donaldson et al:: Factors associated with change in exacerbation frequency in COPD. Respiratory Research 2013 14:79.

\section{Submit your next manuscript to BioMed Central and take full advantage of:}

- Convenient online submission

- Thorough peer review

- No space constraints or color figure charges

- Immediate publication on acceptance

- Inclusion in PubMed, CAS, Scopus and Google Scholar

- Research which is freely available for redistribution

Submit your manuscript at www.biomedcentral.com/submit 